\title{
Nasopharyngeal and oropharyngeal rinses with neutral electrolyzed water prevents COVID-19 in front-line health professionals: A randomized, open-label, controlled trial in a general hospital in Mexico City
}

\author{
RAFAEL GUTIÉRREZ-GARCÍA ${ }^{1}$, JUAN C. DE LA CERDA-ÁNGELES ${ }^{2}$, ARIANA CABRERA-LICONA ${ }^{3}$, \\ IVAN DELGADO-ENCISO ${ }^{4,5}$, NICOLAS MERVITCH-SIGAL ${ }^{6}$ and BRENDA A. PAZ-MICHEL ${ }^{3,4}$ \\ Departments of ${ }^{1}$ Otorhinolaryngology and ${ }^{2}$ Medical Direction, \\ Dr. Enrique Cabrera General Hospital, Mexico City 01620; \\ ${ }^{3}$ Department of Research and Industrial Property, Esteripharma S.A. de C.V., Estado de México 50450; \\ ${ }^{4}$ Department of Molecular Medicine, School of Medicine, Universidad de Colima, Colima 28040; \\ ${ }^{5}$ Cancerology State Institute, Colima State Health Services, Colima 28085; \\ ${ }^{6}$ Department of Medical Direction, Esteripharma México S.A. de C.V., \\ México City 03100, Mexico
}

Received August 29, 2021; Accepted November 4, 2021

DOI: $10.3892 /$ br.2021.1494

\begin{abstract}
The worldwide efforts that healthcare professionals are making in the COVID-19 pandemic is well known, and the high risk of illness and death that front-line staff experience on a daily basis is a reality, despite well-defined protocols for the use of personal protective equipment. In addition, it is well known that vaccination is still faraway to be achieved worldwide and that new variants are emerging, thus additional protective measures must be explored. A prospective open-label randomized controlled clinical trial was performed on front-line medical staff from the Dr. Enrique Cabrera General Hospital in México City to evaluate the effectiveness of nasopharyngeal and oropharyngeal rinses with a neutral electrolyzed water, known as SES, to reduce the risk of COVID-19 disease among front-line, not vaccinated medical staff. A total of 170 volunteers were enrolled and equally divided in a control group and SES group. All members of the trial wore the adequate personal protection equipment at all times while performing their duties, as required by
\end{abstract}

Correspondence to: Dr Brenda A. Paz-Michel, Department of Research and Industrial Property, Esteripharma S.A. de C.V., Jorge Jiménez Cantú Ote 412, 2 de abril, Atlacomulco, Estado de México 50450, Mexico

E-mail: bpaz@esteripharma.com.mx

Abbreviations: SES, neutral electrolyzed water; PPE, personal protective equipment; $R R$, relative risk

Key words: COVID-19, SARS-CoV-2, neutral electrolyzed water, nasal rinses, mouthwashes, prophylaxis standard COVID-19 safety protocols. Additionally, the SES group participants followed a prophylactic protocol with SES (oral and nasal rinses, three times a day for 4 weeks). All participants were monitored for COVID-19 symptoms and disease in a time-frame of 4 weeks and the incidence of illness per group was registered. The relative risk of disease, associated with each treatment was calculated. The presence of COVID-19-positive cases, in the group that received the nasal and oral rinses with SES was $1.2 \%$, while in the group that did not do the SES rinses (control group), it was $12.7 \%$ $(\mathrm{P}=0.0039$ and $\mathrm{RR}=0.09405 ; 95 \% \mathrm{CI}$ of $0.01231-0.7183)$. The prophylactic protocol was demonstrated as a protective factor, in more than $90 \%$, for developing the disease, and without adverse effects. Nasal and oral rinses with SES may be an efficient alternative to reinforce the protective measures against COVID-19 disease and should be further investigated. The present clinical trial was retrospectively registered in the Cuban public registry of clinical trials (RPCEC) database (March 16, 2021; PREVECOVID-19: RPCEC00000357).

\section{Introduction}

SARS-CoV-2, the novel virus in the coronavirus family, is an enveloped single-stranded positive-sense RNA virus that primarily infects the upper respiratory tract. This infection generally causes the COVID-19 disease which has reached pandemic status. Common COVID-19 symptoms include dry cough, dyspnea, headache, fever and fatigue (1). Complications may lead to respiratory failure and death; to such an extent that at the time of writing this article, COVID-19 has caused more than 213.2 million cases and 4.45 million deaths in 219 territories worldwide (https://www.worldometers.info/ coronavirus/) (2). Health workers have experienced high mortality due to COVID-19, Mexico being one of the highest 
with 4,188 deaths, and followed by the USA, UK, Brazil and Russia (3). Even though front-line medical staff are being vaccinated, a specific effective therapy, as well as mass vaccination remain distant goals, with challenging problems such as the appearance of SARS-CoV-2 mutations (4). Prophylactic treatments using aerosolized combinations of medications have been explored with promising results to reduce illness in medical staff $(5,6)$, however these may not be accessible in all countries. Additional measures such as prophylaxis with nasopharyngeal and oropharyngeal rinses are an option, not frequently explored, to mitigate the impact of multiple exposures to this virus (7-14). Recently, the virucidal effect of acidic electrolyzed water (EW); a broad-spectrum antiseptic, over SARS-CoV-2 in vitro has been reported, and it has been postulated that EW may be a safe and accessible option for cleaning oral and nasal cavities to avoid COVID-19 infection $(15,16)$. Neutral electrolyzed water (SES) ( $\mathrm{pH}$ 6.5-7.5) in particular, is an interesting candidate since it is safe to be applied in the nasal and oral mucosa, and since its virucidal action on nonenveloped and enveloped viruses has been demonstrated $(17,18)$. A recent study revealed that the administration of nebulized SES by inhalation to ambulatory COVID-19 patients, in combination with conventional therapy, reduced the disease progression and improved the signs and symptoms after 24-72 h, from first administration (19). In the present study, the effect of using SES with $0.0015 \%$ of reactive species of chlorine and oxygen was studied as a prophylactic protocol (nasopharyngeal and oropharyngeal rinses), to reduce the risk of COVID-19 disease in front-line medical staff, through a prospective open-label randomized controlled trial, conducted in a Mexican COVID-19 hospital.

\section{Materials and methods}

Study design. A prospective, randomized 2-arm, parallel group, open-label clinical trial was conducted from September to November 2020. The aim of the study was to compare the prophylactic effect of using SES, through nasal and oral rinses, together with the use of personal protective equipment (PPE), vs. using only PPE in COVID-19 front-line healthcare professionals at the General Hospital 'Dr. Enrique Cabrera Cosio' in Mexico City, to prevent the COVID-19 disease. The study was approved by the Research Ethics Committee of the Health Ministry of Mexico City (August 31, 2020; Reg. No. 101-010-024-2020) and was conducted in accordance with the ethical international standards established in the Declaration of Helsinki. A written informed consent was obtained from each participant prior to the study. The present clinical trial was registered as PREVECOVID-19: RPCEC00000357 in the Cuban Public Registry of Clinical Trials (RPCEC) database (https://rpcec. sld.cu/en/trials/RPCEC00000357-En/revisions/5137/view).

Study subjects. To participate in the study, the criterion was to be COVID-19 front-line medical staff (nurses and physicians, males or females) from the General Hospital Dr. Enrique Cabrera in México City. The exclusion criteria included medical staff presenting previous or current SARS-CoV-2 infection confirmed by a reverse transcription PCR (RT-PCR) test; medical staff using any type of nasal or oral sanitizer at the moment of recruitment or at any time in the past 2 weeks; taking any antiviral medicine at the moment of recruitment or at any time in the past 3 months; and/or participating in another clinical study. Additionally, the following elimination criteria were used: medical staff that voluntarily decided to suspend the prophylactic treatment or to abandon the study; medical staff who presented two or more symptoms associated with COVID-19 disease (vide infra) and that were confirmed as COVID-19-positive by RT-PCR within the first 14 days of their recruitment; and medical staff that at certain point of the study presented with severe oral or nasal irritability, attributable to the administration of the SES. No participant was vaccinated nor received the vaccine against SARS-CoV-2 during the development of the study; since vaccines were not available in México until December 2020.

Nurses and physicians were invited to participate through an invitation letter. Said invitation letter was given to the leaders of the nursing department and other relevant healthcare departments, so they could distribute the information. Interested medical staff in participating were provided with the details of the study and with the informed consent. Immediately after their recruitment (read and signed informed consent), each participating physician or nurse took one of two identical tokens that were placed inside an opaque plastic container. One token was labeled 'with SES' (treatment group) and the other 'without SES' (control group). Thus, all the participants were randomized between the two groups, until the formation of two groups of 85 members each. All participants provided their medical history, including information concerning diabetes, obesity, hypertension and/or any other disease. All medical staff enrolled in the study were working an average of $25 \mathrm{~h}$ a week in the COVID-19 front-line care of the hospital and all of them were wearing the corresponding PPE (i.e., surgical uniform, N95 mask, eye-sealing glasses and plastic wallet, disposable cap, latex gloves, rubber footwear for hospital use and disposable shoe covers), while working. Additionally, third level care health professionals wore a full protective mask, Dermacare ${ }^{\circledR}$, overalls with zipper, and an integrated hood with elastic hand and ankle cuffs, double disposable boot covers and double latex gloves. Similarly, all medical staff had frequent hand washing with liquid soap ( $2 \%$ chlorhexidine gluconate) and hand disinfection (0.05\% chlorhexidine gluconate and 60-80\% ethyl alcohol). Additionally, disinfection of secondary uniform and footwear (80\% ethyl alcohol) and bath at the end of the working day were routinely performed. All members of the treatment group were provided with directions on how to use the SES as nose rinses and mouthwashes, as well as provided with bottles containing the product. All participants were instructed to immediately inform their leader and the monitor of the study, if any COVID-19 symptoms (vide supra) were experienced during the study, and to be tested for SARS-CoV-2 by RT-PCR (nasopharyngeal swab) in the hospital laboratory. The follow up of each healthcare professional started once they were included in the protocol and finished 4 weeks later.

Prophylactic protocol with SES. All treatment group individuals were provided with a document indicating a detailed description of how to perform the prophylactic protocol (Table I), as well as with: i) four plastic flasks with $30 \mathrm{ml}$ of 
Table I. Prophylactic protocol with neutral electrolyzed water for nasopharyngeal and oropharyngeal rinses.

\begin{tabular}{|c|c|c|}
\hline Directions & $\begin{array}{l}\text { Nasal cavity rinses } \\
\quad\left(\text { EsteriFlu }^{\circledR}\right)\end{array}$ & $\begin{array}{c}\text { Oral cavity rinses } \\
\text { (ESTERICIDE }{ }^{\circledR} \text { Bucofaríngeo) }\end{array}$ \\
\hline How to use & $\begin{array}{l}\text { - Four vertical sprays in each nostril. } \\
\text { - It should be inhaled deeply at the } \\
\text { time of each spray. }\end{array}$ & $\begin{array}{l}\text { - } 10 \mathrm{ml} \text { as mouthwash and gargle, during } 60 \mathrm{sec} . \\
\text { - Spit out. }\end{array}$ \\
\hline Frequency & \multicolumn{2}{|c|}{ - Three times a day } \\
\hline
\end{tabular}

SES each, including a valve to be used for the nasal spray, and ii) four plastic flasks with $240 \mathrm{ml}$ of SES each, including a graduated cap to be used for mouthwashes.

The SES, (pH 6.5-7.5; REDOX potential 750-950 mV; $0.0015 \%$ of active species of chlorine and oxygen) was provided by Esteripharma S.A. de C.V with the commercial product names ESTERICIDE ${ }^{\circledR}$ Bucofaríngeo (COFEPRIS registration no. 1003C2013 SSA) and EsteriFlu ${ }^{\circledR}$ (COFEPRIS registration no. 308C2015 SSA). Nasopharyngeal rinses were performed by applying four sprayings ( $0.4 \mathrm{ml})$ of SES $\left(\right.$ EsteriFlu $\left.^{\circledR}\right)$ to each nostril using the nasal valve, three times a day. Oropharyngeal rinses were performed by gargling $10 \mathrm{ml}$ of SES, during $60 \mathrm{sec}$, three times a day. All participants were informed of the importance of following the protocol and of the correct way of using the nasal sprays and mouthwashes, as well as of immediately reporting any possible side effects attributable to the use of the SES (vide supra).

Diagnosis criteria, outcome measures and follow-up. The primary endpoint was the number of healthcare professionals, nurses, or physicians, with COVID-19 disease confirmed by RT-PCR, between the 14th day since their recruitment and the 28th day of follow up. As part of the COVID-19 diagnosis criteria, all participants were instructed to immediately report to their leader and to their monitor of the protocol when they had at least two of the following COVID-19 signs and symptoms: dry cough, fever $>37.5^{\circ} \mathrm{C}$, headache, myalgia, arthralgia, rhinorrhea, conjunctivitis, pharyngodynia, odynophagia. It is important to mention that all participants were trained medical staff from the front-line of a COVID-19 hospital, and all of them were previously trained to identify and report symptoms, as part of the intrinsic safety protocols of the hospital and the National Ministry of Health (Secretaría de Salud). All the healthcare professionals that had symptoms were immediately isolated and tested for SARS-CoV-2 with an RT-PCR test (nasopharyngeal swab) in order to confirm or reject the COVID-19 diagnosis. Individuals with suspicious symptoms were instructed to immediately report to the hospital laboratory; a nasopharyngeal sample was obtained there and transported with the BIOLOGIX ${ }^{\circledR}$ system, applicable for the collection and transportation of clinical virus samples. SARS-CoV-2 virus detection was carried out by RT-PCR, following the protocols specified by the Institute of Diagnosis and Epidemiological Reference (InDRE) and the health ministry of the country based on WHO guidelines (20). Results were directly reported to tested individuals 48 to $72 \mathrm{~h}$ after sampling through an official email. All the COVID-19-positive medical staff stayed at home and had disease treatment independent of this clinical trial.
The secondary endpoint was the number of healthcare professionals that presented adverse effects (irritation, pain, redness, numbness, bleeding) potentially attributable to the use of the SES; all members of the protocol were instructed to immediately suspend the prophylactic protocol and to report to the main researcher of any moderate or severe potential side effects.

Members of both, control and treatment groups, were followed up weekly through a phone call, during four weeks, monitoring for COVID-19 symptoms and/or confirmation of SARS-CoV-2 infection, as well as potential side effects, as communicated by each participant to the main researcher of the study. All participants were followed up for 4 weeks or until they were confirmed as COVID-19-positive. The Department of Epidemiology of the hospital collected the data and monitored the program.

Blinding. Only the researchers that performed the statistical analyses were blinded.

Sample size. The sample size calculation was based on the number of front-line healthcare professionals that had a confirmed COVID-19 disease by RT-PCR within a period of one month, despite the use of PPE. The sample size was calculated considering that $29 \%$ of such professionals may develop the COVID-19 disease, according to previous reports from Mexican hospitals and considering that the prophylactic protocol with SES may reduce the incidence of the disease by $70 \%$. A total of 57 patients for each group were required to reach the required power (0.8), when the statistical analysis was performed at the level of the one-tailed alpha (0.05). At the end of the study, the statistical power for detecting a difference between the two groups was calculated (one-tailed alpha $=0.05$ ), using the number of patients with disease confirmation, resulting in $86 \%$.

Statistical analysis. Categorical variables were described in percentages $(\%)$, and continuous variables were expressed as the mean \pm standard deviation. Comparisons for the proportions of categorical variables were conducted using Fisher's exact test. Data with normal distribution (e.g., age) were compared between groups, using the unpaired Student's t-test. Relative risk (RR) analysis, with a 95\% confidence interval (CI) for associations between the use of the prophylactic protocol and the development of COVID-19 disease, was used. $\mathrm{P}<0.05$ was considered to indicate a statistically significant difference. The GraphPad Prism version 6.0 for Windows (GraphPad Software, Inc.) was used for all statistical analyses. 


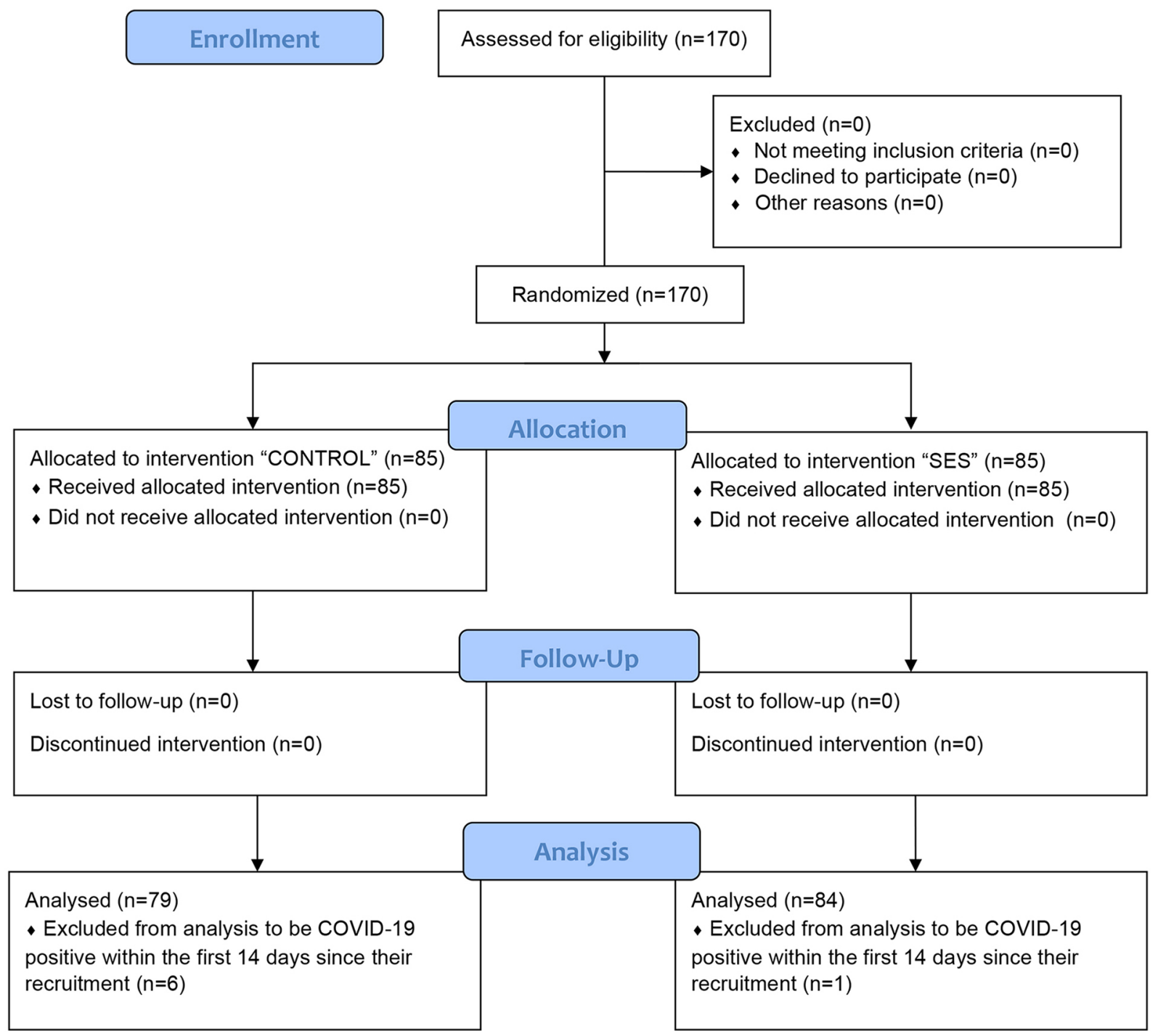

Figure 1. CONSORT 2010 flow diagram displaying the number of screened, included, eliminated, and analyzed patients.

Sample size and statistical power were calculated using the online calculator software by HyLown Consulting LLC to compare 2 proportions: 2-sample, 1-sided for a one-tailed test (http://powerandsamplesize.com/Calculators/Compare-2Proportions/2-Sample-1-Sided) (21).

\section{Results}

A total of 170 healthcare volunteer professionals were randomized in a control or prophylactic protocol group, each with 85 individuals. A total of six individuals were withdrawn from the control group since they presented with COVID-19 disease (symptoms and confirmation by RT-PCR test) within the first fourteen days since their recruitment and one individual from the prophylactic protocol group. The remaining participants were followed-up two additional weeks monitoring for COVID-19 symptoms and conformation of the disease by RT-PCR (Fig. 1).

Healthcare professionals from both groups had similar baseline characteristics. There were 79 individuals in the control group which included 53 nurses $(67.1 \%)$ and 26 physicians (32.9\%); while there were 84 individuals in the prophylactic protocol group which included 56 nurses $(66.7 \%)$ and 28 physicians $(33.3 \%)$. With regard to the sex of the participants, the control group consisted of $72.2 \%$ women, and the prophylactic protocol group had $75.0 \%$, with no significant differences between the groups regarding sex $(\mathrm{P}=0.7242)$ or type of profession $(\mathrm{P}=0.9544)$. The age means revealed a statistically significant difference $(\mathrm{P}=0.0360)$ between the two groups, with $40.94 \pm 7.74$ in the control group and $43.73 \pm 9.01$ in the prophylactic protocol group; particularly in the age group of 30-39 years old, where there were 29 individuals in the control group in this age range and $15(\mathrm{P}=0.0081)$ in the SES group.

Comorbidities were observed in individuals from both groups, $16.5 \%$ in the control group and $29.8 \%$ in the prophylactic protocol group. The relevant comorbidities observed in the control group and the prophylaxis group were obesity [11.4 and $15.5 \%$, respectively $(\mathrm{P}=0.4976)]$, diabetes [3.8 and $6.0 \%$, respectively $(\mathrm{P}=0.7207)]$, and hypertension [5.1 and $8.3 \%$, respectively $(\mathrm{P}=0.5367)]$. Other diseases with less importance for the purpose of the present study were present in $7.6 \%$ of the control group participants, vs. $8.3 \%$ in the SES-treatment group, without statistical significance $(\mathrm{P}=0.0631)$ (Table II). 
Table II. General characteristics of the medical staff enrolled in the clinical trial.

\begin{tabular}{|c|c|c|c|}
\hline $\begin{array}{l}\text { General } \\
\text { characteristics }\end{array}$ & $\begin{array}{l}\text { Control, } \\
\text { N }(\%)\end{array}$ & $\begin{array}{c}\text { Prophylactic protocol } \\
\text { with neutral electrolyzed } \\
\text { water N }(\%)\end{array}$ & P-value \\
\hline Profession & & & 0.9544 \\
\hline Nurses & $53(67.1 \%)$ & $56(66.7 \%)$ & \\
\hline Doctors & $26(32.9 \%)$ & $28(33.3 \%)$ & \\
\hline Sex & & & 0.7242 \\
\hline Male & $22(27.8 \%)$ & $21(25.0 \%)$ & \\
\hline Female & $57(72.2 \%)$ & $63(75.0 \%)$ & \\
\hline Age & $40.94 \pm 7.74^{\mathrm{a}}$ & $43.73 \pm 9.01^{\mathrm{a}}$ & $0.0360^{\mathrm{b}}$ \\
\hline $20-29$ & $6(7.6 \%)$ & $7(8.3 \%)$ & \\
\hline $30-39$ & $29(36.7 \%)$ & $15(17.8 \%)$ & \\
\hline $40-49$ & $37(46.8 \%)$ & $44(52.4 \%)$ & $0.0081^{\mathrm{c}}$ \\
\hline $50-59$ & $5(6.3 \%)$ & $13(15.5 \%)$ & \\
\hline $60-63$ & $2(2.5 \%)$ & $5(6.0 \%)$ & \\
\hline Comorbidities & $13(16.5 \%)$ & $25(29.8 \%)$ & 0.0631 \\
\hline Obesity & $9(11.4 \%)$ & $13(15.5 \%)$ & \\
\hline Diabetes & $3(3.8 \%)$ & $5(6.0 \%)$ & \\
\hline Hypertension & $4(5.1 \%)$ & $7(8.3 \%)$ & \\
\hline Other diseases ${ }^{\mathrm{d}}$ & $6(7.6 \%)$ & $7(8.3 \%)$ & \\
\hline
\end{tabular}

Statistically significant values according to Student's t-test: ${ }^{\mathrm{a}}$ Average and standard deviation, ${ }^{\mathrm{b}} \mathrm{P}=0.05$ and ${ }^{\mathrm{c}} \mathrm{P}=0.01$. ${ }^{\mathrm{d}} \mathrm{Other}$ diseases; control group: vitiligo, obstructive sleep apnea syndrome, hypothyroidism, arthritis, irritable bowel syndrome, gastroesophageal reflux; and prophylactic protocol group: hypothyroidism, arthritis, breast cancer in remission, irritable bowel syndrome, allergic rhinitis, peripheral vascular insufficiency, arrhythmia.

From the 163 volunteers that were followed up during two additional weeks, 10 individuals (12.7\%) from the control group were COVID-19-confirmed by presence of symptoms and SARS-CoV-2 RT-PCR test, whereas only 1 (1.2\%) was confirmed in the prophylaxis protocol group. The difference in the incidence between the two groups was statistically significant with a P-value of 0.0039 . The RR was 0.09405 , with a $95 \% \mathrm{CI}$ of $0.01231-0.7183$ and $\mathrm{P}=0.0039$, indicating a protective factor against COVID-19 disease in more than $90 \%$ for those individuals that followed the prophylactic protocol with SES (Table III), without any side effects.

All the positive individuals in the control or prophylaxis protocol group were nurses; 10 in the control group and 1 in the prophylactic protocol group with SES. Regarding sex, the only one infected individual in the prophylactic protocol group was a female, as well as $80 \%$ of the positive medical staff in the control group. Only two men in the control group were positive to SARS-CoV-2 and none in the SES group, but this was not statistically significant $(\mathrm{P}=0.4884)$ (Table III). Regarding age, the only one confirmed infected individual in the prophylactic protocol group was 43 years old, while in the control group the mean age of positive individuals was $38.1 \pm 5.3$ years old. No statistical significance was observed between developing COVID-19 disease and having a comorbidity. The group that followed the prophylactic protocol with SES had a lower incidence of COVID-19-positive cases and this effect was independent of age, sex, occupation, and former health status (Table III).

\section{Discussion}

This prospective open-label randomized controlled trial was conducted to determine whether there is an association between performing nasopharyngeal and oropharyngeal rinses with SES (0.0015\% of reactive species of chlorine and oxygen), additional to wearing the appropriated PPE, and decreasing the risk of COVID-19 disease among front-line medical staff from a Mexican COVID-19 hospital. Since vaccines were not available in México at the time of the present study (and still are not available, or just partially available in numerous parts of the world) it was important to evaluate alternative therapies in order to increase the protection against the disease. The results revealed that in fact, the group that adhered to the prophylactic protocol with SES, had a significant decrease in the incidence of COVID-19, with only $1.2 \%$ of reported cases; in comparison with the control group, where $18.8 \%$ of individuals were diagnosed with the disease. Thus, a protective factor against the disease in more than $90 \%$ for the health care professionals that followed the prophylactic protocol with SES, was observed. This result allowed us to postulate that the proposed prophylactic protocol of nasal and oral rinses with SES was effective in reducing the viral load in the upper respiratory tract and acting as a protective factor, by reducing the probability of developing the disease. Recently, it has been reported that nasal goblet and ciliated cells are a likely initial invasion site and reservoir of SARS-CoV-2 virus since these cells have a high expression of ACE2 and TMRPSS2; 
Table III. Relative risk association between the general characteristics of COVID-19 individuals and group type.

\begin{tabular}{|c|c|c|c|c|c|}
\hline $\begin{array}{l}\text { General } \\
\text { characteristics }\end{array}$ & $\begin{array}{l}\text { Control } \\
\mathrm{N}(\%)\end{array}$ & $\begin{array}{l}\text { Prophylactic } \\
\text { protocol with } \\
\text { SESN }(\%)\end{array}$ & P-value & $\begin{array}{l}\text { Relative } \\
\text { risk }\end{array}$ & $\begin{array}{l}95 \% \text { Confidence } \\
\text { interval }\end{array}$ \\
\hline $\begin{array}{l}\text { Medical staff } \\
\text { COVID-19- } \\
\text { positive }\end{array}$ & $10(12.7 \%)$ & $1(1.2 \%)$ & $0.0039^{\mathrm{a}}$ & 0.09405 & $0.01231-0.7183$ \\
\hline \multicolumn{6}{|l|}{ Occupation } \\
\hline Nurses & $10(100 \%)$ & $1(100 \%)$ & $0.0034^{\mathrm{a}}$ & 0.09464 & $0.01254-0.7145$ \\
\hline Physicians & 0 & 0 & - & - & - \\
\hline \multicolumn{6}{|l|}{ Sex } \\
\hline Male & $2(20 \%)$ & 0 & 0.4884 & 0 & - \\
\hline Female & $8(80 \%)$ & $1(100 \%)$ & $0.0131^{\mathrm{b}}$ & 0.1131 & $0.01458-0.8770$ \\
\hline Age & $38.10 \pm 5.26^{\mathrm{c}}$ & $43^{c}$ & - & - & - \\
\hline $20-29$ & $1(10.0 \%)$ & 0 & & & \\
\hline $30-39$ & $4(40.0 \%)$ & 0 & 0.4615 & - & - \\
\hline $40-49$ & $5(50.0 \%)$ & $1(100 \%)$ & 0.2822 & - & - \\
\hline $50-59$ & 0 & 0 & 0.0880 & - & - \\
\hline $60-63$ & 0 & 0 & & & \\
\hline \multicolumn{6}{|l|}{ Comorbidities } \\
\hline Obesity & 0 & 0 & & & \\
\hline Diabetes & 0 & 0 & & & \\
\hline Hypertension & 0 & 1 & 1 & - & - \\
\hline Others $^{\mathrm{d}}$ & 0 & 1 & 1 & - & - \\
\hline
\end{tabular}

${ }^{\mathrm{a}} \mathrm{P}=0.01$ and ${ }^{\mathrm{b}} \mathrm{P}=0.05$; Statistically significant values: ${ }^{\mathrm{c}}$ Average and standard deviation, and ${ }^{\mathrm{h}}$ hypothyroidism.

it was also determined that salivary glands, epithelial cells of the tongue and fibroblasts of oral mucosa express ACE2, explaining that both the nasopharynx and oropharynx have the highest viral loads (22-25). Additionally, it has been demonstrated in vitro that acidic electrolyzed water had a virucidal effect on SARS-CoV-2 (16), while SES demonstrated similar virucidal activity against the respiratory influenza viruses H5N1 and H9N2, and over gastrointestinal noroviruses $(17,18)$. Interestingly, in the case of the influenza virus, no viral particles and proteins were detected following SES exposure and it has been postulated that the REDOX potential of SES, breaks chemical bonds and causes changes in surface proteins, destruction of the viral envelope, inactivation of viral enzymes, and destruction of viral nucleic acids (26). Similar effects over SARS-CoV-2 virus have been described for the hypochlorous acid, an active chlorine species present in SES (27). This may explain the low incidence of SARS-CoV-2-positive cases in the group that followed the prophylactic protocol, suggesting that when exposed, the rinses not only reduced the viral load by dragging, but also by inactivating viral particles, and thus preventing their union with cellular receptors and the infection, given that viral proteins are susceptible to denaturalization (26). In this regard, other substances with oxidizing potential have been proposed for oropharyngeal washes and even in dilutions for irrigation of the nose, but their irritant effect on mucous membranes is discussed (7-13). Therefore, the use of SES for these purposes has the advantage of not being irritating and having an effective oxidant potential against viral particles; it should be noted that no individual using SES reported related side effects, therefore they did not discontinue its use.

The proposed scheme for using SES three times a day required that the rinses were performed at the beginning of the day, at midday and at the end of the day, trying to cover the entire active day of the individuals and not just the working day, so it is possible that the rinses with electrolyzed water may effectively reduce the risk of infection even when containment measures are decreased. A more detailed study concerning this should be carried out to corroborate this point, particularly considering the exposure and protective conditions of the regular population, in order to demonstrate the utility of the SES in preventing COVID-19 disease at this level. Additionally, the use of SES by individuals who are ill may help to locally inactivate the viral loads in the mouth and nose, and thus to reduce the transmission rates. With respect to this point, it has been reported that the administration of SES to ambulatory patients by nebulization, in combination with conventional therapy, reduced the disease progression and improved the signs and symptoms after 24-72 h of the first administration (19). Thus, the present study is consistent with the hypothesis of an efficient inactivation of the virus, in the mouth and respiratory tract. In the present study, only one-third of the population from each group consisted of physicians, and none of them fell ill. Additionally, it was observed that the highest number 
of COVID-19-positive individuals were female nurses from the control group; this is consistent with another study from the literature, that describes a high incidence of SARS-CoV-2 infection in nurses, since they spend more time with patients than physicians do (28). Other studies concerning the risk of infection considered populations with similar size with regard to the sex of the individual and concluded that the probability of getting infected is equal for both sexes $(29,30)$. Thus, for the present study it was concluded that the highest incidence in the female population was due to the higher percentage $(>70 \%)$ of enrolled individuals being women.

By contrast, a recent epidemiological study revealed that COVID-19 patients had a mean age in the mid-40s (30), and consistent with the observations in their study, the infected individuals of both groups belonged to this age group. However, the sample size between the two groups was quite different, thus hypothesizing that the use of SES may reduce the risk of contagion.

Finally, with respect to comorbidities, it is clear that hypertension, diabetes, and obesity, increase the risk of infection and severity of the COVID-19 disease (31). Since the Mexican population has a high prevalence of the aforementioned comorbidities, in the present study it was evaluated whether there was an increased risk of disease in individuals with the aforementioned preexisting conditions, despite the use of SES. The results revealed no increased risk of contracting the disease that could be associated with comorbidities. However, the sample size of the volunteers with such comorbidities was not extensive enough, and therefore in order to establish whether the use of SES could reduce the risk of infection in these individuals, a larger sample must be analyzed.

Our study has certain limitations, first, the lack of a control group treated with a placebo, such as a saline solution. Nevertheless, it is important to mention that this possibility was evaluated and it was concluded that there was a high risk of spreading the disease by producing fomites with such rinses without an antiseptic effect $(12,32)$. According to the World Health Organization, 'there is no evidence that regularly rinsing the nose with saline has protected people from infection with the new coronavirus' (33).

Additionally, there are several studies in the literature demonstrating that the throat and sputum are abundant in viral particles and that even numerous asymptomatic people have detectable levels of viral RNA in the oropharynx $(34,35)$. Furthermore, certain authors recommend caution when using nasal saline irrigation, since this practice could potentially disperse viral particles or contaminate surfaces in the immediate vicinity (32).

Another limitation of our study was the small number of available RT-PCR tests and the consequent impossibility to analyze, at least once a week, all of the participants in order to identify asymptomatic but infected cases. Nevertheless, the present study provided sufficient evidence to postulate that SES with $0.0015 \%$ of active species of chlorine and oxygen is useful to prevent the COVID-19 disease. When SES is administered as a nasal spray and as a mouthwash, in addition to PPE, it may improve the protection against the COVID-19 disease, as it has been demonstrated in the present study and due to its known potential to inactivate viruses, such as the SARS-CoV-2. It is urgent to develop more studies, particularly considering the daily activities of the general population, in order to demonstrate that SES is safe and effective to improve personal protection, and potentially to reduce the risk of contagion and transmission rates in the general population worldwide. In conclusion, nasopharyngeal and oropharyngeal rinses with SES may be an efficient alternative to reinforce the protective measures against COVID-19 disease and should be further investigated.

\section{Acknowledgements}

The authors would like to thank Esteripharma S.A. de C.V. company for providing the SES for the study, as Esteriflu ${ }^{\circledR}$ and Estericide ${ }^{\circledR}$ Bucofaríngeo products.

\section{Funding}

No funding was received.

\section{Availability of data and materials}

The data that support the findings of this study are available from the corresponding author on reasonable request.

\section{Authors' contributions}

RGG designed the study and conducted the data acquisition. JCDLCA performed the data acquisition. ACL performed the data analysis. IDE performed the data analysis and interpretation. NMS helped with the validation and supply of the neutral electrolyzed water used in the study. RGG, JCA and IDE confirm the authenticity of all the raw data. BAPM participated in the design of the study. All authors helped to prepare, and have read and approved the final manuscript.

\section{Ethics approval and consent to participate}

The present study was approved by the Research Ethics Committee of the Ministry of Health of Mexico City (Reg. No. 101-010-024-2020) in accordance with the ethical international standards established in the Declaration of Helsinki. Each participant provided their written informed consent, and data was processed according to national and international data protection laws.

\section{Patient consent for publication}

Not applicable.

\section{Competing interests}

The authors RGG, JCA and IDE declare that they have no competing interests. ACL, NMS and BPM state that they are employees at Esteripharma S.A. de C.V. company but did not participate in the decision to publish the results of the study, nor in the selection of the volunteers or in its development.

\section{References}

1. Wang MY, Zhao R, Gao LJ, Gao XF, Wang DP and Cao JM: SARS-CoV-2: Structure, biology, and structure-based therapeutics development. Front Cell Infect Microbiol 10: 724, 2020 . 
2. Worldometer: COVID Live Update: $213,211,782$ Cases and 4,452,192 Deaths from the Coronavirus, 2021.

3. Amnesty International: Mapping health worker deaths from COVID-19, 2020.

4. Jogalekar MP, Veerabathini A and Gangadaran P: SARS-CoV-2 variants: A double-edged sword? Exp Biol Med (Maywood) 246: 1721-1726, 2021.

5. Liu X, Liu Y, Wang L, Hu L, Liu D and Li J: Analysis of the prophylactic effect of thymosin drugs on COVID-19 for 435 medical staff: A hospital-based retrospective study. J Med Virol 93: 1573-1580, 2021.

6. Dubina MV, Gomonova VV, Taraskina AE, Vasilyeva NV and Sayganov SA: Pathogenesis-based preexposure prophylaxis associated with a low risk of SARS-CoV-2 infection in healthcare workers at a designated COVID-19 hospital: A pilot study. BMC Infect Dis 21: 536, 2021.

7. Cegolon L, Javanbakht $M$ and Mastrangelo G: Nasal disinfection for the prevention and control of COVID-19: A scoping review on potential chemo-preventive agents. Int J Hyg Environ Health 230: 113605, 2020.

8. O'Donnell VB, Thomas D, Stanton R, Maillard JY, Murphy RC, Jones SA, Humphreys I, Wakelam MJO, Fegan C, Wise MP, et al Potential role of oral rinses targeting the viral lipid envelope in SARS-CoV-2 infection. Function (Oxf) 1: zqaa002, 2020

9. Carrouel F, Conte MP, Fisher J, Gonçalves LS, Dussart C, Llodra JC and Bourgeois D: COVID-19: A recommendation to examine the effect of mouthrinses with $\beta$-cyclodextrin combined with citrox in preventing infection and progression. J Clin Med 9: 1126,2020

10. Bidra AS, Pelletier JS, Westover JB, Frank S, Brown SM and Tessema B: Rapid in-vitro inactivation of severe acute respiratory syndrome coronavirus 2 (SARS-CoV-2) using povidone-iodine oral antiseptic rinse. J Prosthodont 29: 529-533, 2020.

11. Caruso AA, Del Prete A and Lazzarino AI: Hydrogen peroxide and viral infections: A literature review with research hypothesis definition in relation to the current covid-19 pandemic. Med Hypotheses 144: 109910, 2020.

12. Meyers C, Robison R, Milici J, Alam S, Quillen D, Goldenberg D and Kass R: Lowering the transmission and spread of human coronavirus. J Med Virol 93: 1605-1612, 2021.

13. Seneviratne CJ, Balan P, Ko KKK, Udawatte NS, Lai D, Ng DHL, Venkatachalam I, Lim KS, Ling ML, Oon L, et al: Efficacy of commercial mouth-rinses on SARS-CoV-2 viral load in saliva: Randomized control trial in Singapore. Infection 49: 305-311, 2021

14. Huijghebaert S, Hoste L and Vanham G: Essentials in saline pharmacology for nasal or respiratory hygiene in times of COVID-19. Eur J Clin Pharmacol 77: 1275-1293, 2021.

15. Yan P, Daliri EBM and Oh DH: New clinical applications of electrolyzed water: A review. Microorganisms 9: 136, 2021.

16. Takeda Y, Uchiumi H, Matsuda S and Ogawa H: Acidic electrolyzed water potently inactivates SARS-CoV-2 depending on the amount of free available chlorine contacting with the virus. Biochem Biophys Res Commun 530: 1-3, 2020.

17. Moorman E, Montazeri N and Jaykus LA: Efficacy of neutral electrolyzed water for inactivation of human norovirus. App Environ Microbiol 83: e00653-17, 2017.

18. Tamaki S, Bui VN, Ngo LH, Ogawa H and Imai K: Virucidal effect of acidic electrolyzed water and neutral electrolyzed water on avian influenza viruses. Arch Virol 159: 405-412, 2014.

19. Delgado-Enciso I, Paz-Garcia J, Barajas-Saucedo CE, Mokay-Ramírez KA, Meza-Robles C, Lopez-Flores R, Delgado-Machuca M, Murillo-Zamora E, Toscano-Velazquez JA, Delgado-Enciso J, et al: Safety and efficacy of a COVID-19 treatment with nebulized and/or intravenous neutral electrolyzed saline combined with usual medical care vs. usual medical care alone: A randomized, open-label, controlled trial. Exp Ther Med 22: 915, 2021.

20. Corman VM, Landt O, Kaiser M, Molenkamp R, Meijer A Chu DK, Bleicker T, Brünink S, Schneider J, Schmidt ML, et al: Detection of 2019 novel coronavirus $(2019-\mathrm{nCoV})$ by real-time RT-PCR. Eurosurveillance 25: 2000045, 2020.
21. HyLown Consulting LLC: Power and Sample Size Calculators Compare 2 Proportions: 2-Sample, 1-Sided Calculator: 1. 2013.

22. Sungnak W, Huang N, Bécavin C, Berg M, Queen R, Litvinukova M, Talavera-López C, Maatz H, Reichart D, Sampaziotis F, et al: SARS-CoV-2 entry factors are highly expressed in nasal epithelial cells together with innate immune genes. Nat Med 26: 681-687, 2020.

23. Zou L, Ruan F, Huang M, Liang L, Huang H, Hong Z, Yu J, Kang M, Song Y, Xia J, et al: SARS-CoV-2 viral load in upper respiratory specimens of infected patients. N Engl J Med 382: $1177-1179,2020$

24. To KK, Tsang OT, Leung WS, Tam AR, Wu TC, Lung DC, Yip CC, Cai JP, Chan JM, Chik TS, et al: Temporal profiles of viral load in posterior oropharyngeal saliva samples and serum antibody responses during infection by SARS-CoV-2: An observational cohort study. Lancet Infect Dis 20: 565-574, 2020.

25. Xu H, Zhong L, Deng J, Peng J, Dan H, Zeng X, Li T and Chen Q: High expression of ACE2 receptor of $2019-\mathrm{nCoV}$ on the epithelial cells of oral mucosa. Int J Oral Sci 12: 8, 2020.

26. Morita C, Sano K, Morimatsu S, Kiura H, Goto T, Kohno T, Hong WU, MiyoshiH, Iwasawa A, Nakamura Y, et al: Disinfection potential of electrolyzed solutions containing sodium chloride at low concentrations. J Virol Methods 85: 163-174, 2000.

27. Giarratana N, Rajan B, Kamala K, Mendenhall M and Reiner G: A sprayable Acid-Oxidizing solution containing hypochlorous acid (AOS2020) efficiently and safely inactivates SARS-Cov-2: A new potential solution for upper respiratory tract hygiene. Eur Arch Otorhinolaryngol 278: 3099-3103, 2021.

28. Liu SY, Kang XL, Wang CH, Chu H, Jen HJ, Lai HJ, Shen SH, Liu D and Chou KR: Protection procedures and preventions against the spread of coronavirus disease 2019 in healthcare settings for nursing personnel: Lessons from Taiwan. Aust Crit Care 34: 182-190, 2021

29. Peckham H, de Gruijter NM, Raine C, Radziszewska A, Ciurtin C, Wedderburn LR, Rosser EC, Webb K and Deakin CT: Male sex identified by global COVID-19 meta-analysis as a risk factor for death and ITU admission. Nat Commun 11: 6317, 2020.

30. Li J, Huang DQ, Zou B, Yang H, Hui WZ, Rui F, Yee NTS, Liu C, Nerurkar SN, Kai JCY, et al: Epidemiology of COVID-19: A systematic review and meta-analysis of clinical characteristics, risk factors, and outcomes. J Med Virol 93: 1449-1458, 2021.

31. Ejaz H, Alsrhani A, Zafar A, Javed H, Junaid K, Abdalla AE Abosalif KOA, Ahmed Z and Younas S: COVID-19 and comorbidities: Deleterious impact on infected patients. J Infect Public Health 13: 1833-1839, 2020

32. Kimura KS, Freeman MH, Wessinger BC, Gupta V, Sheng Q, Ching Huang L, Von Wahlde K, Das SR, Chowdhury NI and Turner JN: Interim analysis of an open-label randomized controlled trial evaluating nasal irrigations in non-hospitalized patients with coronavirus diesease 2019. Int Forum Allergy Rhinol 10: 1325-1328, 2020.

33. World Health Organization (WHO): Coronavirus disease (COVID-19) advice for the public: Mythbusters. https://www. who.int/emergencies/diseases/novel-coronavirus-2019/advice-forpublic/myth-busters\#saline. Accessed October, 2021.

34. Pan Y, Zhang D, Yang P, Poon LLM and Wang Q: Viral load of SARS-CoV-2 in clinical samples. Lancet Infect Dis 20: 411-412, 2020.

35. Wölfel R, Corman VM, Guggemos W, Seilmaier M, Zange S, Müller MA, Niemeyer D, Jones TC, Vollmar P, Rothe C, et al: Virological assessment of hospitalized patients with COVID-2019. Nature 581: 465-469, 2020.

This work is licensed under a Creative Commons Attribution-NonCommercial-NoDerivatives 4.0 International (CC BY-NC-ND 4.0) License. 